Abant Tıp Dergisi

Araştırma Makalesi / Cilt 9 Sayı 3 Yıl 2020
Abant Medical Journal

Research Article /Volume 9 Issue 3 Year 2020

\title{
Günlük Yaşam Aktivitelerinden Korkma Envanterinin Türkçe Versiyonunun Psikometrik Özelliklerinin Değerlendirmesi ile Kültürel Adaptasyonu
}

\section{Cross-Cultural Adaptation into Turkish Assessing its Psychometric Properties: The Fear of Daily Activities Questionnaire}

\author{
Nuray ALACA ID \\ Acıbadem Mehmet Ali Aydınlar Üniversitesi, Fizyoterapi ve Rehabilitasyon Bölümü, Ataşehir, İstanbul - Türkiye
}

\section{Öz}

GiRiş ve AMAÇ: Günlük Yaşam Aktivitelerinden Korkma Envanteri (GYAK), kronik bel ağrılı hastaların ağrı nedeniyle yapmaktan kaçındığı en sık on aktiviteyi listelemektedir. Envanter, Türkçe'ye daha önce çevrilmemiş ve geçerlik ile güvenirliği araştırılmamıştır. Mevcut çalışmada kronik bel ağrılı (KBA) hastalarda günlük aktivitelere karşı korku envanterinin (GYAK) Türkçe çevirisinin, geçerlik ve güvenirliğini araştırmayı amaçlanmaktadır.

YÖNTEM ve GEREÇLER: GYAK'ın Türkçe çevirisi uluslararası kılavuzlardaki gibi tamamlandıktan sonra 60 KBA hastası (38 kadın, ortalama yaş: $44,31 \pm 13,05$ yıl) sosyo-demografik bilgi formunu, Oswestry Disabilite Indeksi (ODi), Tampa Kinezyofobi Ölçeği (TKÖ) ve Korku-Kaçınma İnanışlar Envanterini (KKIA) doldurmuştur. GYAK, 72-90 saat sonra test tekrar analizi için tekrarlanmıştır. İstatiksel analiz SPSS 21.0 ile yapılmış ve $p<0,05$ istatiksel olarak anlamlı kabul edilmiştir.

BULGULAR: GYAK'ın Türkçe versiyonunun mükemmel iç tutarlılığa (Cronbach $\alpha$ katsayısı $=0,821$ ) ve test-tekrar test güvenirliğine [sınıf içi korelasyon katsayısı $(I C C=0,834)$ ] sahip olduğu belirlenmiştir. Ayrıca, GYAK envanteri; TKÖ ve KKiA ile orta düzeyde, ODi ile yüksek düzeyde ilişkili bulunmuştur $(p<0,001)$.

TARTIŞMA ve SONUÇ: Mevcut çalışmada GYAK'ın Türkçe versiyonunun mükemmel iç tutarlığa, test-tekrar test güvenilirliğine ve orta ile yüksek dereceli yapı geçerliğine sahip olduğu gösterilmiştir. Türkiye'de yapılacak araştırmalar için kronik bel ağrılı hastalarda rehabilitasyon sırasında bu envanterin kullanabileceğini belirlenmiştir.

Anahtar Kelimeler: Bel ağrısı; geçerlik ve güvenirlik; günlük yaşam aktiviteleri

\section{Abstract}

INTRODUCTION: The Fear of Daily Activities Questionnaire (FDAQ) lists ten activities that report that patients with chronic low back pain (CLP) often have a fear of activity due to pain. The questionnaire has not been translated into Turkish and its validity and reliability have not been investigated. In this study, it is aimed to investigate the cultural adaptation and psychometric properties of FDAQ in CLP, into Turkish.

METHODS: Sixty stroke patients (38 women, mean age: $44.31 \pm 13,05$ ) after completing the translation of the FDAQ as per the international guidelines, sociodemographic data form, Oswestry Disability Index (ODI), Tampa Kinesiophobia Scale (TKS) and Fear-Avoiding Beliefs Questionnaire (FBQ) and filled the FDAQ. 72-90 hours later, the FDAQ was repeated for test-retest analysis. Statistical analysis was performed with SSPS 21.0 and $p<0.05$ was considered statistically significant.

RESULTS: The Turkish version of FDAQ had excellent internal consistency (Cronbach $\alpha$ coefficient $=0,821$ ) and test-retest reliability (intraclass correlation coefficient (ICC $=0,834)$. In addition, FDAQ was found to be medium relationship between TKÖ, KKIA and a high level with the ODI questionnaire $(p<0.001)$.

DISCUSSION and CONCLUSION: The Turkish version of the FDAQ was found to have a medium-high level of structure and high level content validity, excellent internal consistency, and test re-reliability. For research in Turkey was determined that questionnaire can be used with patients CLP during rehabilitation.

Keywords: Activities of daily living; low back pain; reliability and validity

\section{Gíiiş}

En yaygın kronik ağrı nedenlerinden biri olan kronik bel ağrısı (KBA), ağrı ve engelliğin önde gelen nedenlerinden biridir $(1,2)$. Önemli bir sosyoekonomik etkiye sahip olan KBA'nın yaşam boyu prevelansı \% 84 oranındadır (3). Literatürde akut KBA'lı kişilerin yaklaşık \% 25'inin bir yıl boyunca tekrarlayan atak geçirdiği, \% 7 ila 10'unun kronik ağrılı bir hale geldiği bildirilmektedir $(4,5)$. Kronik ağrı yaşayan bireylerde korku ve anksiyete (ağrı ile ilişkili) 
duyguları görülmektedir. Bu durum bireyin aktiviteden uzak durmasına, depresyon yaşamasına yol açmaktadır. KBA'lı bireyler yaşadıkları ağrı dolayısıyla günlük aktiviteler sırasında, çocuk bakımında, sosyal ile iş yaşamlarında problemler yaşamaktadır (6). Ayrıca bu ağrı bireyin fonksiyonel ile sosyal durumunun ve yasam kalitesinin daha da azalmasına katkıda bulunmaktadır $(7,8)$.

Bel ağrılı hastalarda her türlü egzersizin ve aktivitenin ağrıyı artıracağı düşüncesi olan "Korku kaçınma modeli" gelişmektedir. Birey bu nedenle egzersiz ve aktiviteden kaçınmaktadır (9-11). Korku kaçınma modelinden üretilen kinezyofobi terimi; artan ağrı algısı sonucu kişinin hareket etmekten korkması ve ağrı ile başa çıkmada kaçınma veya yüzleşme cevabı gösterememesidir. Kaçınma, korku ile artış göstererek hareket korkusunu oluşturur $(12,13)$. Kesitsel ve proprioseptif çalışmalarda kinezyofobinin bel ağrısında fonksiyonel engelliğin çeşitli safhalarında, çeşitli ağrı koşullarında önemli bir belirteç olduğu belirtilmiştir. Ek olarak kinezyofobinin yüksekliğinin gelecekteki engellilik ve bel ağrısı konusunda bir tahmin aracı olarak kullanabileceği gözlenmektedir (14-16).

Korku kaçınma modelini yenmek için birçok biyopsikososyal yaklaşım denenmektedir. Bu müdahaleler arasında hasta eğitimi $(15,17)$, kademeli egzersiz $(18,19)$ ve kademeli maruz bırakma $(12,20)$ bulunmaktadır. Kademeli maruz bırakmanın, genel aktivite düzeylerini arttırmak için oldukça faydalı olduğu literatürde belirtilmektedir. Dereceli maruz bırakma hipotezlerinin test edilmesi, spesifik aktivitelerin korkusunu değerlendirmek için güvenilir ve geçerli araçlara ihtiyaç duyduğundan George ve arkadaşları tarafından Günlük Yaşam Aktivitelerinden Korkma Envanteri (GYAK) geliştirilmiştir. Bu envanter, kronik bel ağrılı hastaların ağıı nedeniyle yapmaktan kaçındığı en sık 10 aktiviteyi listelemektedir (21). Envanter, Türkçe'ye daha önce çevrilmemiş ve geçerlik ile güvenirliği araştırımamıştır. Bu nedenle mevcut çalışmada kronik bel ağrılı hastalarda günlük aktivitelere karşı korku envanterinin Türkçe çevirisinin, geçerlik ve güvenirliğini araştırmayı amaçlamaktayız.

\section{GEREÇ ve YÖNTEMLER}

\section{Çeviri ve Kültürlerarası Adaptasyon}

GYAK'ın Türkçe çevirisi ve psikometrik değerlendirmesi için envanterin orijinal halini geliştiren Steven Z. George'den mail yoluyla izin aldıktan sonra çalışmaya Acıbadem Üniversitesi ve Acıbadem Sağlık Kuruluşları Tıbbi Araştırma Etik Kurulu'ndan onay (2018-6/13) alınmıştır. Adaptasyon yapılırken Beaton ve arkadaşlarının önerdiği uluslararası kılavuzlardaki gibi beş aşama (çeviri, sentez, geri çeviri, uzman komite ve pilot çalışma) gerçekleştirilmiştir (22). illk aşamada çalışma hakkında bilgisi olmayan bir Ingilizce çevirmeni ve çalışma hakkında bilgisi olan bir fizyoterapist tarafından Ingilizce envanter Türkçe'ye çevrilmiştir. Her iki kişide akıcı şekilde İngilizce ve Türkçe biliyor ve ana dili gibi dilleri konuşabiliyorlardı. Çeviriler, birbirinden bağımsız şekilde tamamlandıktan sonra ikinci aşamaya geçilerek, çevirinin sentezi yapılmıştır. Sentezden sonraki hali iki dili de iyi bilen biri tarafından herhangi bir kavramsal hata veya tutarsızlığı bulmak için gözden geçirilmiştir. Üçüncü aşamada envanter anadili İngilizce olan Türkçe'yi de iyi derecede konuşabilen iki kişi tarafından İngilizce'ye geri çevrilmiştir. Her iki çevirmenin de çalışma hakkında bilgisi yoktur ve orijinal envantere ulaşım sağlamamışlardır. Dördüncü aşamada çevrilen İngilizce envanterin, orijinal İngilizce envanter ile karşılaştırılması ve Türkçe çevirisi hakkındaki raporları içeren bilgiler uzman komite (çalışmanın metodunu oluşturan ve geliştiren araştırıcı, dil uzmanları ve 4 tercüman) tarafından değerlendirilip, son hali verilmiştir. Beşinci aşamada ön test yapılmıştır (22). Envanterin psikometrik özelliklerini değerlendirmek için iç tutarlılık, test-tekrar güvenirliği, iç ve yapı geçerliliği değerlendirmeleri 
yapılmıştır $(22,23)$.

\section{Pilot çalışma}

Fizyoterapi ve Rehabilitasyon Bölümüne KBA nedeniyle başvuran çalışmaya alınma ve dışlanma kurallarına uyan $10 \mathrm{KBA}$ hasta katılımcı (6 kadın, 4 erkek ortalama yaş \pm standart hata: $42,17 \pm 11,12$ yıl) pilot çalışmaya katılmıştır. Envanter her katılımcı tarafından yapılmış ve envanteri veren fizyoterapist ile kişilerin yüz yüze röportaj yapması sağlanmıştır. Katılımcılar soruları okuyup, maddeleri anlaşılabilirlik yönünden değerlendirdiler. Anlamakta zorluk çektikleri cümle ile kelimeler fizyoterapist tarafından not edilmiş ve silme veya değiştirme için katılımcıların çeşitli öğeler önermelerine izin verilmiştir.

\section{İcerik Geçerliği}

İçerik geçerliğini değerlendirmek için Popham (23) tarafından açıklanan yöntem kullanılmıştır. Uzman komite üyeleri $(22,23)$ ve 4 fizyoterapist, GYAK'daki her bir maddenin, temel yapısına uygun ve ilgili olup olmadığını belirtmiştir. Her uzman tarafından maddelere uygun görülen yüzdeler verilmiş ve ardından uzmanların verdikleri yüzdelerin ortalaması alınmıştır. GYAK'nın son hali Ek'te gösterilmektedir.

\section{Katılımcılar}

Fizik Tedavi ve Rehabilitasyon bölümüne başvuran KBA'ı 60 hasta katılımcı (yaş 18- 70 yaş arası) çalışmaya dahil edilmiştir. Üç aydan az bel ağrısı varlığı olan, bel ağrısında kırmızı bayraklar olan bel-diz-boyun ağrısına bağlı operasyon, tümör, hamilelik, enfeksiyon, ağır kronik sistemik hastalık, kauda ekina sorunları olan hastalar, Türkçe okuma ve anlama konusunda problemi olanlar, herhangi bir psikiyatrik tanı ile tedavi gören hastalar çalışmaya dahil edilmemiştir. Hastaların sosyodemografik özellikleri ve istirahat ile hareketteki ağrıları görsel ağrı skalası (GAS, 0-10) yardımı ile kaydedilmiştir (24). ìlk gün Oswestry Disabilite Indeksi (ODi), Tampa
Kinezyofobi Ölçeği (TKÖ), Korku-Kaçınma Inanışlar Envanteri (KKIA) ve GYAK değerlendirmeleri hastaların yapması sağlanmıştır. Güvenirlik için test tekrar analizi kullanılmış ve $72-90$ saat sonra GYAK tekrarlanmıştır. Katılımcıların bu zaman aralığında fiziksel veya psikolojik bir değişiklik yaşayıp yaşamadıklarını değerlendirmek için Global Değişim Derecesi (GRC) sorgulanmıştır. GRC, çok daha iyi hissetmek (+2) ile çok daha az iyi hissetmek (-2) arasında değişen 5 puanlık Likert ölçeğinde puanlanmıştır (25). Önceki test zamanına göre daha fazla ya da daha az iyi hissettiğini bildiren katılımcılar (5 hasta, 3 erkek, 2 kadın) test-tekrar analizinden çıkarılmıştır.

\section{Yapı Geçerliliği}

Yapı geçerliliği, belirli bir ölçütteki puanların, ölçülen yapılarla ilgili türetilmiş hipotezlerle tutarlı olmasını ve diğer ölçütlerle ne ölçüde ilişkili olduğunu ifade etmektedir. Bu nedenle yapı geçerliliğini değerlendirmek için ODi, TKÖ ve KKiA tüm katılımcılara yapılmıştır. (26).

\section{Ölçme Araçları}

Oswestry Disabilite İndeksi, 10 alt gruptan oluşur ve bel ağrısına bağlı fonksiyonel yetersizlik düzeyini belirmek için Fairbank ve arkadaşları tarafından geliştirilmiş̧ir (27). Türkçe geçerlik ve güvenirliği Yakut ve arkadaşları tarafından (28) 2004 yılında gösterilmiş olan ODi'nin iç tutarlıığı (Cronbach'ın alfa katsayı: 0,918) ve test tekrar güvenirliği (sınıf içi korelasyon katsayısı: 0,938) mükemmel olarak belirlenmiştir. Alt grupları (ağrı şiddeti, kaldırma-taşıma, kendine bakım, yürüyüş, ayakta durma, oturma, uyku, yolculuk etme, cinsel yaşam ve sosyal hayat) $0-5$ arasında puanlanmaktadır. Toplam skor arttıkça fonksiyonel yetersizlik düzeyi de artmaktadır (27, 28).

Tampa Kinezyobi Ölçeği (TKÖ), hareket ve tekrar yaralanma korkusunu ölçmek amacıyla geliştirilmiş, 17 soruluk bir ölçektir. Ölçeğin orijinali 1991 'de Miller, Kopri ve Todd tarafından 
geliştirilmiş ancak yayınlanmamıştır. Vlaeyen ve arkadaşları, 17 sorudan oluşan orijinal ölçeği, geliştiren araştırmacıların izniyle, 1995'de yeniden yayınlamışlardır (29). Türkçe geçerlik ve güvenirliği Yılmaz ve arkadaşları tarafından (30) 2011 yılında gösterilmiş olan TKÖ’nin test tekrar güvenirliği (sınıf içi korelasyon katsayısı: 0,806) mükemmel olarak belirlenmiştir. Ölçekte puanın artması (17-68 puan aralığı), bireyin hareket ve tekrar yaralanma korkusunun yüksekliğini gösterir (29).

Korku-Kaçınma İnanışlar Envanteri (KKIA), fiziksel aktivite ve işin etkilerine bağlı olarak korkukaçınma inanışlarını değerlendirmek amacıyla 1993'de Waddell ve arkadaşları tarafından geliştirilen 16 soruluk bir envanterdir (31). Türkçe geçerlik ve güvenirliği Bingül ve Baş Aslan tarafından (32) 2013 yılında gösterilmiş olan KKiA'nın iç tutarlılığı (Cronbach'ın alfa katsayı: 0,82 (fiziksel aktivite), 0,88 (iş)] ve test tekrar güvenirliği [sınıf içi korelasyon katsayısı: 0,68 (fiziksel aktivite), 0,94 (iş)] orta ile yüksek olarak belirlenmiştir. İki alt ölçeği vardır. Bunlar iş ve fiziksel aktivitedir. İş bölümü 11 sorudan, fiziksel aktivite bölümü 5 sorudan [hiç katılmıyorum (0 puan), tamamen katılıyorum (6 puan)] oluşmaktadır. Değerlendirmede toplam puan 0'a yaklaştıkça bölüm içinde korku-kaçınma davranışında azalma, maksimum puana yaklaştıkça ise korku-kaçınma davranışında artma olduğu kabul edilmektedir. Her iki alt ölçek puanları bağımsız olarak da kullanılabilmektedir. $(31,32)$.

Günlük Yaşam Aktivitelerinden Korkma Envanteri (GYAK), Steven Z. George ve arkadaşları tarafindan spesifik aktivitelerin korkusunu değerlendirmek için geliştirilmiştir. Bu envanter, kronik bel ağrılı hastaların ağrı nedeniyle yapmaktan kaçındığı en sık 10 aktiviteyi listelemektedir (21). Bu aktiviteler 1 saatten fazla oturma, 30 dakikadan fazla ayakta durma, 30 dakikadan fazla yürüme, 9 kilodan az ağırlık kaldırma gibi bireylerin günlük yaşamında çok sık kullandıkları etkinliklerdir. Envanter, Türkçe'ye daha önce çevrilmemiş ve geçerlik ile güvenirliği araştırılmamıştır. GYAK, açık uçlu yanıtlar için de ek olarak iki seçenek sunmaktadır. Böylece bu hastaların ağrı nedeniyle korktukları aktivitelere ek örnekler ve derecelendirmeler yapması sağlanmaktadır. Fakat bu sorular analizlere katılmaz. Hastalar her aktiviteyi, 0'dan (korkmuyorum) 100'e (maksimum korku)'ya kadar olan bir sayısal değerlendirme skalası kullanarak derecelendirir. On standart faaliyet için puanlar toplanıp 10'a bölünerek skorlama yapılır (21).

Global Değişim Derecesi (GRC) semptom şiddeti, tedaviye yanıt ve tedavinin etkinliği için kullanılabilen sübjektif bir ölçektir. Kronik bel ağrılı hastalarda mükemmel test tekrar güvenirliliğine sahip olduğu gösterilmiştir (sınıf içi korelasyon katsayısı: 0,90) (33). Katılımcıların bu zaman aralığında fiziksel veya psikolojik bir değişiklik yaşayıp yaşamadıklarını değerlendirmek için beşli likert ölçeğinde GRC katılımcılara sorgulanmıştır [Çok daha iyi hissetmek (+2) ile çok daha az iyi hissetmek (-2)] (25).

\section{İstatistik analiz}

Elde edilen verilerin analizinde SPSS paket istatistik programının (Statistical Package for the Social Sciences Inc; Chicago, IL, ABD) 21.0 sürümü kullanıımıştır. Kategorik değişkenler, kişi sayısı (n) ve sıklık yüzdesi ile, sayısal veriler ise ortalama \pm standart hata olarak özetlenmiştir. Veriler normal dağılım göstermediğinden cinsiyet karşılaştırmaları Mann-Whitney $U$ testi ile yapılmıştır. Korelasyon analizinde, Spearman korelasyon analiz yöntemi kullanımış ve korelasyon katsayısı ( $r$ ) değeri; 0,01 - 0,29 düşük, $0,30-0,70$ orta, 0,71 - 0,99 yüksek, 1,00 mükemmel düzeyde ilişki olarak değerlendirilmiştir.

İç tutarlık Cronbach'ın alfa katsayıları kullanılarak (mükemmel > 0,80; yeterli 0,70-0,79; yetersiz $<0,70)$ belirlenmiştir. Test tekrar güvenirlik analizinde sınıf içi korelasyon katsayısı (ICC) 
kullanılmıştır. Katsayı 0,81-1,00 arasında ise mükemmel; 0,61-0,80 arasında çok iyi; 0,41-0,60 arasında iyi; 0.21-0.40 arasında kötü, 0.00-0.20 arası ise zayıf olarak tanımlanır $(26,34,35)$.

\section{BULGULAR}

Uzman komite üyeleri, orijinal indekste yer alan başlığın "günlük aktivite" olarak çevrilmemesini "günlük yaşam aktiviteleri" adını almasını önerdiler. Pilot çalışmadaki hasta katılımcılar ise beli çevirme lafının anlaşılamadığını bu nedenle en uygun kelimenin beli döndürme olduğunu belirtiler. Bu hali ile envanterin son hali oluşturulmuştur. Son hali, komite uzmanlarının hepsi tarafından değerlendirilmiş ve öğelerin \% 100 'ü temel yapılarıyla uyumlu olarak belirlenmiştir. İçerik geçerliliği bu nedenle \% 100 olarak belirlenmiştir.

Katılımcıların yaş ile vücut kitle indeksi ortalama ve standart hataları sırasıyla $44.31 \pm 13,05$ yıl ve $29.05 \pm 2,18 \mathrm{~kg} / \mathrm{m} 2$ iken, katılımcılarımızın \% 63,3'ü kadın, \%46,7'si üniversite mezunu ve $\% 76,7$ 'si evli idi (Tablo 1). GAS istiharat düzeyleri $3,92 \pm 4,20$ iken hareket esnasında GAS düzeyi yükselerek $6,85 \pm 1,22$ değerine ulaşmaktaydı. ODi skorlarının ise ortalama $43,88 \pm 16,28$ çıkması katılımcıların bize daha çok şiddetli disabilitede olduğunu göstermiştir. Ayrıca TKÖ $(44,60 \pm 6,28)$, KKiA-İş $(32,08 \pm 10,39)$, KKiA-Fiziksel Aktivite $(23,53 \pm 6,90)$ ve $\operatorname{GYAK}(48,05 \pm 18,22)$ düzeyleri ortalama ölçek değerlerinden yüksek olarak saptanmıştır (Tablo 1).

Yapı geçerliliği için GYAK'ın diğer envanterlerle ilişkisi araştırımıştır (Tablo 2). GYAK'ın yapı geçerliliği tüm envanterlerde orta düzeyde ilişkili $(r=0,385-679 ; p=0,005-<0.001)$ çıkarken ODi envanteri ile yüksek düzeyde $(r=0,749 ; p<0.001)$ ilişkili olarak belirlenmiştir.

GYAK'ın Türkçe versiyonunun ölçek güvenirliği iç tutarlılık ölçme yöntemlerinden Cronbach $\alpha$ katsayısı hesaplaması ile yapılmış ve sonuçta mükemmel iç tutarlılığa (Cronbach $\alpha$ katsayısı = 0.821) sahip olduğu belirlenmiştir. Envanterin zamana karşı güvenirliği için test-tekrar test güvenirliği kullanılmış olup bunun için sınıf içi korelasyon katsayısı hesaplanmıştır. Sınıf içi korelasyon katsayısının mükemmel olduğu (ICC= $0,834)$ saptanmıştır.

Tablo 1. Sosyodemografik Özellikler ve Klinik Anket Sonuçları

\begin{tabular}{|c|c|c|}
\hline Parametreler & $\begin{array}{l}\text { n sayısı } \\
\text { veya } \\
\text { ortalama } \pm \text { standart } \\
\text { hata }\end{array}$ & Sıklık (\%) \\
\hline \multicolumn{3}{|l|}{ Cinsiyet } \\
\hline Kadın & 38 & 63,3 \\
\hline Erkek & 22 & 26,7 \\
\hline Yaş & $44.31 \pm 13,05$ & \\
\hline Vücut kitle indeksi & $29.05 \pm 2,18$ & \\
\hline \multicolumn{3}{|l|}{ Eğitim } \\
\hline Okuma yazma yok & 2 & 3,3 \\
\hline İlkokul & 10 & 16,7 \\
\hline Ortaokul & 12 & 20 \\
\hline Lise & 8 & 13,3 \\
\hline Üniversite & 28 & 46,7 \\
\hline \multicolumn{3}{|l|}{ Medeni durum } \\
\hline Evli & 46 & 76,7 \\
\hline Bekâr & 14 & 23,3 \\
\hline GAS (istirahat) & $3,92 \pm 4,20$ & \\
\hline GAS (hareket) & $6,85 \pm 1,22$ & \\
\hline ODİ & $43,88 \pm 16,28$ & \\
\hline TKÖ & $44,60 \pm 6,28$ & \\
\hline \multicolumn{3}{|l|}{ KKİA } \\
\hline KKİA-İş & $32,08 \pm 10,39$ & \\
\hline KKİA-Fiziksel Aktivite & $23,53 \pm 6,90$ & \\
\hline KKİA-Toplam & $54,86 \pm 14,29$ & \\
\hline GYAK & $48,05 \pm 18,22$ & \\
\hline
\end{tabular}

Tablo 2. Günlük Yaşam Aktivitelerinden Korkma Anketinin diğer parametrelerle olan ilişkisi

\begin{tabular}{|c|c|c|}
\hline Parametre & $\begin{array}{l}\text { GYAK(korelasyon } \\
\text { katsayısı; r) }\end{array}$ & $\begin{array}{l}\text { GYAK } \\
\text { (p değeri) }\end{array}$ \\
\hline GAS (istirahat) & 385 & 0,005 \\
\hline GAS (hareket) &, 553 & 0,000 \\
\hline ODİ & ,749 & 0,000 \\
\hline TKÖ & 679 & 0,000 \\
\hline \multicolumn{3}{|l|}{ KKİA } \\
\hline KKİA-İş & ,402 & 0,001 \\
\hline KKİA-Fiziksel Aktivite &, 502 & 0,000 \\
\hline KKİA-Toplam &, 450 & 0,000 \\
\hline
\end{tabular}

GAS, Görsel ağrı skalası; ODi, Oswestry Disabilite İndeksi; TKÖ, Tampa Kinezyofobi Ölçeği; KKiA, Korku-Kaçınma İnanışlar Anketi; GYAK, Günlük Yaşam Aktivitelerinden Korkma Anketi 


\section{TARTIŞMA}

GYAK, kronik bel ağrılı hastaların ağrı nedeniyle yapmaktan kaçındığı en sık 10 aktiviteyi listelemekte ve hastaların bu aktivitelerden duyduğu korkuyu derecelendirmektedir (21). Mevcut çalışmada GYAK'ın Türkçe versiyonunun kültürel adaptasyonu ve psikometrik özelliklerini araştırmak amaçlanmıştır ve oluşturulan Türkçe versiyonunun yapı geçerliliğinin orta-yüksek olduğu, mükemmel iç tutarlılık ile test tekrar güvenirliğine sahip olduğu belirlenmiştir.

Hareket korkusunun yani kinezyofobinin KBA'lı bireylerde günlük aktiviteleri sınırlandıran bir faktör olduğu gösterilmiş ve rehabilitasyon sürecini olumsuz olarak etkilediği bildirilmiştir. Kinezyofobi, "acılı yaralanma veya yeniden yaralanmaya karşı savunmasızlık hissinden kaynaklanan aşırı, irrasyonel ve zayıflatıcı fiziksel hareket ve aktivite korkusu" olarak tanımlanır. Son yıllarda araştırmacıların odaklandığı bir konudur $(36,37)$. TKÖ'de 37 puanın üzerindeki değer yüksek derece kinezyofobi olarak tanımlanmaktadır (38). Mevcut çalışmada hastaların hareket korkusu ortalamaları 37 puandan yüksek olduğu için katılımcıların hareket korkusu yaşadığı belirlenmiştir. Ayrıca, 2019 yılında KBA'lı hastalarla yaptığımız başka bir çalışmada da mevcut çalışmaya benzer sonuçlar alınmıştır ve bu yüksek hareket korkusunun ağrı seviyesi ile disabilite ile ilişkili olmadığı gösterilmiştir (39). Mevcut çalışmada da GYAK envanteri TKÖ ile yükseğe yakın bir düzeyde ilişki gösterirken, ağrı seviyeleri ile orta seviyede ilişki de olduğu görüldü. Bu durum hastaların ağrı düzeyi ile hareket korkuları arasında fazla bir ilişki olmadığını, hastaların az ağrısı olsa da hareket korkuları olabileceğini bize göstermektedir.

Engellilik ile korku kaçınma davranışı arasındaki ilişkiyi araştırmak için birçok çalışma yapılmıştır. Fritz ve ark. (8) iş yaşamı nedeniyle akut bel ağrısı olan ve fizyoterapi gören hastalarda yaptıkları çalışmalarında uygulanan rehabilitasyon sonuçlarının ilk başta olumlu olsa da sonrasında hastalarda, uzun süreli işe gitmeme ve devamlı fonksiyonel yetersizlik oluşabileceğini göstermişlerdir. Bu durumunun sebebinin yüksek korku-kaçınma inanışları ile ilişkili olduğunu bildirmişlerdir (8). Yine tedavi gören akut bel ağrılı hastalarında yapılan bir çalışmada iki ay sonra gelişen fonksiyonel yetersizliğin en iyi belirtecinin korku kaçınma inanışları ile ilgili olduğu gösterilmiştir (40). Vlayen ve Linton (41) çalışmalarında eğer hastalarda ağrıya bağı korku ve kaçınma davranışları varsa bu hastaların bazılarında kronik bir problemin gelişebilme olasılı̆̆ı olduğunu bildirmişlerdir. Akut bel ağrısında yapılmış başka bir çalışmada hastaların ağrı ve korku-kaçınma inanışları, tedaviyle baskılandığında hastaların aktivite düzeyinde artış gözlenmiştir. Ayrıca hastaların sosyal ve günlük yaşam aktivitelerine katılım düzeylerinin arttığı da gösterilmiştir (14). Mevcut çalışmada literatüre benzer şekilde KBA'lı hastaların KiKA sonuçları yüksek çıkmıştır. Ayrıca KiKA skorları GYAK ile yükseğe yakın orta düzeyde ilişkili olduğu belirlenirken, ODi ile GYAK'ın yüksek düzeyde ilişkili olduğu görülmüştür. Böylece literatüre uyumlu biçimde disabilite seviyelerinin aktivite korkusu ile ilişkisi olduğu belirlenmiştir.

GYAK yeni bir envanterdir, ancak kas-iskelet ağrısı olan hastalar için spesifik aktivite korkusunu değerlendirmenin tek yolu değildir. Günlük Aktiviteler-Kısa Elektronik Versiyon Fotoğraf Serileri, Leeuw ve arkadaşları tarafından geliştirilen (16) KBA olan hastalarda günlük aktivitelere algılanan korkunun değerlendirilmesi için ve iyi güvenilirlik ve geçerliliğe sahip olduğu gösterilen bir ölçme aracıdır. Resimsel Etkinlik Korkusu Ölçeği-Servikal ölçme aracı ise boyun aktiviteleri ile ilişkili hareket korkusunun değerlendirilmesi için Turk ve ark. (42) tarafından geliştirilmiştir ve ayrıca iyi bir güvenilirlik ve geçerliliğe sahip olduğu gösterilmiştir. $\mathrm{Bu}$ resimsel ölçüm teknikleri, bireyin kendini raporlamasını sağlar ve aktiviteyi daha ayrıntılı olarak tasvir etme avantajına sahiptir $(16,42)$. Ölçme yöntemlerinde hastanın kaldırdığı veya taşıdığı nesnenin tam boyutu, şekli ve doğası 
resimsel yöntemlerde gösterilmiştir. Orijinal envanteri geliştiren George ve arkadaşları (21) envanterin iyi bir güvenirliğe sahip olduğunu ama tam olarak her hareketi ölçemediğini sadece belirli faaliyetlerin korkusunu değerlendirdiğini belirtmiştir. Ayrıca resimli ölçme araçlarının da bu konuda kullanılabileceğini ve hastanın yazı şeklindeki ölçme araçlarındansa, resimli ölçme araçlarını daha iyi kavrayabileceğini belirtmişlerdir. Bu durumu envanterin kısıtlılığı olarak açıklamışlardır. Envanterdeki açık uçlu sorulardaki cevapların rehabilitasyonda mutlaka kayda alınması ve ona göre önlemler alınması gerektiğini bildirmişlerdir.

Bu çalışma GYAK'ın Türkçe versiyonunun psikometrik özelliklerini araştırmak için yapılmıştır. Tedavi sonrasında, bu ölçeğin ne kadar değiştiği ile ilgili bir ölçümün yapılamaması çalışmanın sınırlııklarından birisidir. Diğer bir limitasyon ise test-tekrar süresinin az olmasıdır. Bunun nedeni; hastaların tedavi alması gerektiği için global değişim derecesinin tedavi arasında ve sonrasında çok değişebileceğini öngörmemizdir. Sonuç olarak, çevirisini ve kültürel adaptasyonunu yaptığımız GYAK'ın Türkçe versiyonunun mükemmel iç tutarlığa, test-tekrar test güvenilirliğine ve orta ile yüksek dereceli yapı geçerliliğine sahip olduğunu göstererek Türkiye'de yapılacak araştırmalar ve tedaviler için kronik bel ağrılı hastalarda rehabilitasyon sırasında bu envanterin kullanabileceğini belirledik.

Bilgilendirilmiş Onam: Katılımcılardan yazıı onam alınmıştır.

Çıkar Çatışması: Yazarlar çıkar çatışması beyan etmemişlerdir.

Finansal Destek: Yazarlar finansal destek beyan etmemişlerdir.

\section{KAYNAKLAR}

1. Hoy DG, Smith E, Cross M, Sanchez-Riera L, et al. The global burden of musculoskeletal conditions for 2010: an overview of methods. Ann Rheum Dis 2014;73(6), 982-989.
2. Vos $T$, Flaxman $A D$, Naghavi $M$, et.al. Years lived with disability (YLDs) for 1160 sequelae of 289 diseases and injuries 1990-2010: a systematic analysis for the Global Burden of Disease Study 2010. The Lancet 2012; 380(9859), 2163-2196.

3. Walker BF. The prevalence of low back pain: a systematic review of the literature from 1966 to 1998. Clinical Spine Surgery 2000; 13(3), 205-217.

4. Fritz JM, George SZ, Delitto A. The role of fearavoidance beliefs in acute low back pain: relationships with current and future disability and work status. Pain 2001;94(1), 7-15.

5. Stanton TR, Henschke N, Maher CG. et al. After an episode of acute low back pain, recurrence is unpredictable and not as common as previously thought. Spine 2008;33(26), 2923-2928.

6. Sielski R, Rief W, Glombiewski JA. Efficacy of biofeedback in chronic back pain: a meta-analysis. Int J Behav Med 2017;24(1), 25-41.

7. Foster NE. Barriers and progress in the treatment of low back pain. BMC medicine 2011; 9(1), 108.

8. Fritz JM, George SZ. Identifying psychosocial variables in patients with acute work-related low back pain: the importance of fear-avoidance beliefs. Phys Ther 2012; 82(10), 973-983.

9. Pfingsten $M$, Kröner-Herwig $B$, Leibing $E$, Kronshage $U$. Validation of the German version of the fear-avoidance beliefs questionnaire (FABQ). Eur J Paın 2000;4(3), 259266.

10. Staerkle R, Mannion AF, Elfering A, et al. Longitudinal validation of the fear-avoidance beliefs questionnaire (FABQ) in a Swiss-German sample of low back pain patients. Eur Spine J 2004; 13(4), 332-340.

11. Georgoudis G, Papathanasiou G, Spirapoulos P, Katsoulakis K. Cognitive assesment of musculoscletal painwith a newly validated Greek version of the Fear Avoidance Beliefs Questionnaire (FABQ). Eur J Paın 2007;11, 341-351

12. Vlaeyen JW, de Jong J, Geilen $M$, Heuts $P H$, van Breukelen G. Graded exposure in vivo in the treatment of pain-related fear: a replicated single-case experimental design in four patients with chronic low back pain. Behav Res Ther;2001;39(2), 151-166.

13. Kori SH. Kinisophobia: a new view of chronic pain behavior. Pain Manage 1990;35-43.

14. Swinkels-Meewisse IE, Roelofs J, Verbeek AL, Oostendorp RA, Vlaeyen JW. Fear-avoidance beliefs, disability, and participation in workers and nonworkers with acute low back pain. Clın J Paın 2006;22(1), 45-54.

15. Coudeyre E, Tubach F, Rannou F, et al. Effect of a simple information booklet on pain persistence after an acute episode of low back pain: a non-randomized trial in a primary care setting. PLoS One 2007; 2(8).

16. Leeuw M, Goossens ME, Linton SJ, Crombez G, Boersma K, Vlaeyen JW. The fear-avoidance model of 
musculoskeletal pain: current state of scientific evidence. J Behav Med 2007;30(1), 77-94.

17. Burton AK, Waddell G, Tillotson KM, Summerton N. Information and advice to patients with back pain can have a positive effect: a randomized controlled trial of a novel educational booklet in primary care. Spine 1999;24(23), 2484.

18. George SZ, Fritz JM, Bialosky JE, Donald DA. The effect of a fear-avoidance-based physical therapy intervention for patients with acute low back pain: results of a randomized clinical trial. Spine 2003; 28(23), 2551-2560.

19. Lindström I, Öhlund C, Eek C, et al. The effect of graded activity on patients with subacute low back pain: a randomized prospective clinical study with an operantconditioning behavioral approach. Phys Ther 1992;72(4), 279-290.

20. Linton SJ, Boersma K, Jansson $M$, Overmeer $T$, Lindblom $\mathrm{K}$, Vlaeyen JW. A randomized controlled trial of exposure in vivo for patients with spinal pain reporting fear of work-related activities. Eur J Paın 2008; 12(6), 722-730.

21. George SZ, Valencia C, Zeppieri Jr G, Robinson ME. Development of a self-report measure of fearful activities for patients with low back pain: the fear of daily activities questionnaire. Phys Ther 2009;89(9), 969-979.

22. Beaton DE, Bombardier C, Guillemin F, Ferraz MB. (2000). Guidelines for the process of cross-cultural adaptation of self-report measures. Spine 2000;25(24), 3186-3191.

23. Mokkink LB, Terwee CB, Patrick DL, et al. The COSMIN checklist for assessing the methodological quality of studies on measurement properties of health status measurement instruments: an international Delphi study. Qual Life Res 2010;19(4), 539-549.

24. Popham WJ. Criterion-referenced assessment. Englewood Cliffs (NJ): Prentice-Hall; 1978.

25. Price DD, McGrath PA, Rafii A, Buckingham B. The validation of visual analogue scales as ratio scale measures for chronic and experimental pain. Pain 1983;17(1), 45-56.

26. Kamper SJ, Maher CG, Mackay G. Global rating of change scales: a review of strengths and weaknesses and considerations for design. JMMT 2009;17(3), 163170.

27. Terwee CB, Bot SD, de Boer MR, et al. Quality criteria were proposed for measurement properties of health status questionnaires. J Clın Epıdemıol 2007;60(1), 3442.

28. Fairbank JC, Couper J, Davies JB, O'brien JP. The Oswestry low back pain disability questionnaire. Physiotherapy 1980;66(8), 271-273.

29. Yakut $E$, Düger $T$, Oksüz $C$, et al. Validation of the Turkish version of the Oswestry Disability Index for patients with low back pain. Spine. 2004; 29:581-585

30. Vlaeyen JW, Kole-Snijders AM, Boeren RG, et al. Fear of movement/(re)injury in chronic low back pain and its relation to behavioral performance. Pain. 1995; 62:363-372.

31. Yilmaz ÖT, Yakut Y, Uygur F, Uluğ N. Tampa Kinezyofobi Ölçeği'nin Türkçe versiyonu ve test-tekrar test güvenirliği. Fizyoterapi Rehabilitasyon 2001;22(1), 44-9.

32. Waddell G, Newton M, Henderson I, Somerville $D$, Main CJ. A Fear-Avoidance Beliefs Questionnaire (FABQ) and the role of fear-avoidance beliefs in chronic low back pain and disability. Pain 1993; 52(2), 157-168.

33. Bingül ÖÖ, Aslan UB. Korku-Kaçınma İnanışlar Envanteri'nin Türkçe'ye uyarlanması, güvenirliği ve geçerliği. Fizyoterapi ve Rehabilitasyon 2013;24(1), 135-43.

34. Costa LOP, Maher CG, Latimer J, et al. Clinimetric testing of three self-report outcome measures for low back pain patients in Brazil: Which one is the best? Spine. 2008; 33:2459-2463.

35. Çelik D, Malkoç M, Martin R. Evidence for reliability, validity and responsiveness of Turkish Foot and Ankle Ability Measure (FAAM). Rheumatol Int 2016; 36(10), 1469-1476.

36. Alaca N, Safran EE, Karamanlargil Ai, Timucin E. Translation and cross-cultural adaptation of the extended version of the Nordic musculoskeletal questionnaire into Turkish. JMNI 2019; 19(4), 472.

37. Al-Obaidi SM, Nelson RM, Al-Awadhi S, Al-Shuwaie N. The role of anticipation and fear of pain in the persistence of avoidance behavior in patients with chronic low back pain. Spine 2000;25(9), 1126-1131.

38. Lüning Bergsten $C$, Lundberg $M$, Lindberg $P$, Elfving $B$. Change in kinesiophobia and its relation to activity limitation after multidisciplinary rehabilitation in patients with chronic back pain. Dısabıl Rehabıl 2012; 34(10), 852-858.

39. Vlaeyen JW, Kole-Snijders AM, Rotteveel AM, Ruesink $\mathrm{R}$, Heuts $\mathrm{PH}$. The role of fear of movement/(re) injury in pain disability. J Occup Rehabıl 1995;5(4), 235-252.

40. Alaca N, Kaba H, Atalay A. Associations between the severity of disability level and fear of movement and pain beliefs in patients with chronic low back pain. J Back Muscul Rehab. 2019; 33(5):785-791.

41. Klenerman L, Slade IM. The prediction of chronicity in patients with an acute attack of low back pain in a general practice setting. Spine 1995; 20, 478-484

42. Vlaeyen, J. W., \& Linton, S. J. (2000). Fear-avoidance and its consequences in chronic musculoskeletal pain: a state of the art. Pain, 85(3), 317-332.

43. Turk, D. C., Robinson, J. P., Sherman, J. J., Burwinkle, T., \& Swanson, K. (2008). Assessing fear in patients with cervical pain: development and validation of the Pictorial Fear of Activity Scale-Cervical (PFActS-C). Pain, 139(1), 55-62. 